\title{
Thermal Analysis of Power Semiconductor Converters
}

\author{
Adrian Plesca \\ Gheorghe Asachi Technical University of Iasi \\ Romania
}

\section{Introduction}

Power devices may fail catastrophically if the junction temperature becomes high enough to cause thermal runaway and melting. A much lower functional limit is set by temperature increases that result in changes in device characteristics, such as forward breakover voltage or the recovery time, and failure to meet device specifications.

Heat generation occurs primarily within the volume of the semiconductor pellet. This heat must be removed as efficiently as possible by some form of thermal exchange with the ambient, by the processes of conduction, convection or radiation.

Heat loss to the case and heat-sink is primarily by conduction. Heat loss by radiation accounts for only $1-2 \%$ of the total and can be ignored in most situations. Finally, loss from the heat-sink to the air is primarily by convection. When liquid cooling is used, the heat loss is by conduction to the liquid medium through the walls of the heat exchanger. Heat transfer by conduction is conveniently described by means of an electrical analogy, as it shows in Table 1.

\begin{tabular}{cccccc}
\hline \multicolumn{3}{c}{ THERMAL } & \multicolumn{4}{c}{ ELECTRICAL } \\
\hline Quantity & Symbol & $\begin{array}{c}\text { Measure } \\
\text { unit }\end{array}$ & Quantity & Symbol & $\begin{array}{c}\text { Measure } \\
\text { unit }\end{array}$ \\
\hline $\begin{array}{c}\text { Loss } \\
\text { power }\end{array}$ & $\mathrm{P}$ & $\mathrm{W}$ & $\begin{array}{c}\text { Electric } \\
\text { current }\end{array}$ & $\mathrm{I}$ & $\mathrm{A}$ \\
\hline $\begin{array}{c}\text { Temperature } \\
\text { variation }\end{array}$ & $\Delta \theta$ & $0 \mathrm{C}$ & Voltage & $\mathrm{U}$ & $\mathrm{V}$ \\
\hline $\begin{array}{c}\text { Thermal } \\
\text { resistance }\end{array}$ & $\mathrm{R}_{\mathrm{th}}$ & ${ }^{0} \mathrm{C} / \mathrm{W}$ & $\begin{array}{c}\text { Electrical } \\
\text { resistance }\end{array}$ & $\mathrm{R}$ & $\Omega$ \\
\hline $\begin{array}{c}\text { Thermal } \\
\text { capacity }\end{array}$ & $\mathrm{C}_{\mathrm{th}}$ & $\mathrm{J} /{ }^{0} \mathrm{C}$ & $\begin{array}{c}\text { Electrical } \\
\text { capacity }\end{array}$ & $\mathrm{C}$ & $\mathrm{F}$ \\
\hline Heat & $\mathrm{Q}$ & $\mathrm{J}$ & $\begin{array}{c}\text { Electrical } \\
\text { charge }\end{array}$ & $\mathrm{Q}$ & $\mathrm{As}$ \\
\hline $\begin{array}{c}\text { Thermal } \\
\text { conductivity }\end{array}$ & $\lambda$ & $\mathrm{W} / \mathrm{m}^{0} \mathrm{C}$ & $\begin{array}{c}\text { Electrical } \\
\text { conductivity }\end{array}$ & $\sigma$ & $1 / \Omega \mathrm{m}$ \\
\hline
\end{tabular}

Table 1. Thermal and electrical analogy 
Taking into account the thermal phenomena complexity for power semiconductor devices it is very difficult to study the heating processes both in steady-state or transitory operating conditions, using the traditional analytical equations. The modeling concepts have their strength for different grades of complexity of the power circuit. It is important to achieve an efficient tradeoff between the necessary accuracy, required simulation speed and feasibility of parameter determination, (Kraus \& Mattausch, 1998). Approaches to simulate these processes have already been made in earlier work. Numerical programs based on the method of finite differences are proposed in (Wenthen, 1970), or based on formulation of charge carrier transport equations, (Kuzmin et al., 1993). A physical model using the application of continuity equation for description of the carrier transport in the low doped layer of structures is proposed in (Schlogl et al., 1998). A simple calculation procedure for the time course of silicon equivalent temperature in power semiconductor components based on the previously calculated current loading is shown in (Sunde et al., 2006). In order to take into account the nonlinear thermal properties of materials a reduction method based on the Ritz vector and Kirchoff transformation is proposed in (Gatard et al., 2006).

The work described in (Chester \& Shammas, 1993) outlines a model which combines the temperature dependent electrical characteristics of the device with its thermal response. The most papers are based on the thermal RC networks which use the PSpice software, (Maxim et al., 2000; Deskur \& Pilacinski, 2005). In (Nelson et al., 2006) a fast Fourier analysis to obtain temperature profiles for power semiconductors is presented. Electro-thermal simulations using finite element method are reported in (Pandya \& McDaniel, 2002) or combination with the conventional RC thermal network in order to obtain a compact model is described in (Shammas et al., 2002). Most of the previous work in this field of thermal analysis of power semiconductors is related only to the power device alone. But in the most practical applications, the power semiconductor device is a part of a power converter (rectifier or inverter). Hence, the thermal stresses for the power semiconductor device depend on the structure of the power converter. Therefore, it is important to study the thermal behaviour of the power semiconductor as a component part of the converter and not as an isolated piece. In the section 2, the thermal responses related to the junction temperatures of power devices have been computed. Parametric simulations for transient thermal conditions of some typical power rectifiers are presented in section 3 . In the next section, the $3 \mathrm{D}$ thermal modelling and simulations of power device as main component of power converters are described.

\section{Transient thermal operating conditions}

The concept of thermal resistance can be extended to thermal impedance for time-varying situations. For a step of input power the transient thermal impedance, $Z_{\text {thjCDC }}(t)$, has the expression,

$$
Z_{t h j C D C}(t)=\frac{\Delta \theta_{j C}(t)}{P}
$$

where:

$Z_{\text {thjCDC }}(t)$ means junction-case transient thermal impedance;

$\Delta \theta_{\mathrm{jc}}(\mathrm{t})$ - difference of temperature between junction and case at a given time $\mathrm{t}$;

$\mathrm{P}$ - step of input power.

The transient thermal impedance can be approximated through a sum of exponential terms, like in expression bellow, 


$$
Z_{t h j C D C}(t)=\sum_{j=1}^{k} r_{j}\left(1-e^{-\frac{t}{\tau_{j}}}\right)
$$

where $\tau_{j}=r_{j} C_{j}$ means thermal time constant.

The response of a single element can be extended to a complex system, such as a power semiconductor, whose thermal equivalent circuit comprises a ladder network of the separate resistance and capacitance terms shown in Fig. 1.

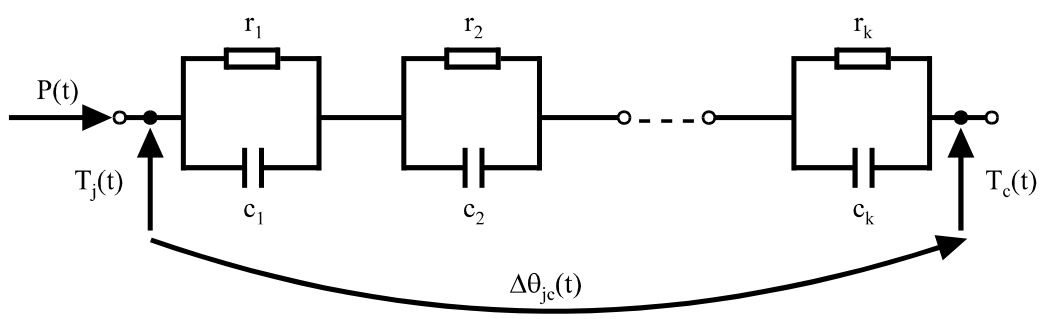

Fig. 1. Transient thermal equivalent circuit for power semiconductors

The transient response of such a network to a step of input power takes the form of a series of exponential terms. Transient thermal impedance data, derived on the basis of a step input of power, can be used to calculate the thermal response of power semiconductor devices for a variety of one-shot and repetitive pulse inputs. Further on, the thermal response for commonly encountered situations have been computed and are of great value to the circuit designer who must specify a power semiconductor device and its derating characteristics.

\subsection{Rectangular pulse series input power}

Figure 2 shows the rectangular pulse series and the equation (3) describes this kind of input power.

$$
P(t)=\left\{\begin{array}{lll}
P_{F M} & \text { if } & n T \leq t \leq n T+\theta \\
0 & \text { if } & n T+\theta<t \leq(n+1) T
\end{array}\right.
$$

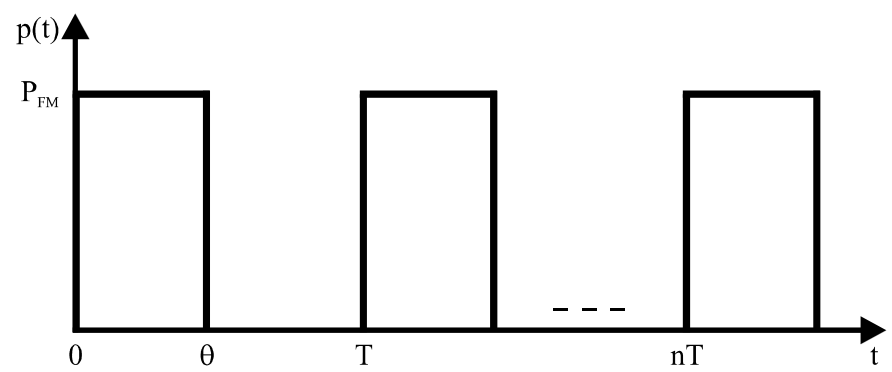

Fig. 2. Rectangular pulse series input power

The thermal response is given by the following equation, 


$$
\Delta \theta_{j C(n+1)}(t)=\left\{\begin{array}{l}
P_{F M} \sum_{i=1}^{k} r_{i}\left[1-\frac{e^{-\frac{t-n T}{T_{i}}}\left(1-e^{-\frac{(n+1) T}{T_{i}}}\right)-\left(1-e^{-\frac{n T}{T_{i}}}\right) e^{-\frac{T-\theta}{T_{i}}}}{1-e^{-\frac{T}{T_{i}}}}\right] \text { if } n T \leq t \leq n T+\theta, \\
P_{F M} \sum_{i=1}^{k} r_{i} e^{-\frac{t-n T-\theta}{T_{i}}} \frac{1-e^{-\frac{\theta}{T_{i}}}}{1-e^{-\frac{T}{T_{i}}}}\left(1-e^{-\frac{(n+1) T}{T_{i}}}\right) \text { if } n T+\theta<t \leq(n+1) T
\end{array}\right.
$$

For a very big number of rectangular pulses, actually $n \rightarrow \infty$, it gets the relation:

$$
\Delta \theta_{j C \infty}(t)=\left\{\begin{array}{c}
P_{F M} \sum_{i=1}^{k} r_{i}\left(1-e^{-\frac{t}{T_{i}}}\right) \frac{1-e^{-\frac{T-\theta}{T_{i}}}}{1-e^{-\frac{T}{T_{i}}}} \text { if } n T \leq t \leq n T+\theta, \\
P_{F M} \sum_{i=1}^{k} r_{i} e^{-\frac{t-\theta}{T_{i}}} \frac{1-e^{-\frac{\theta}{T_{i}}}}{1-e^{-\frac{T}{T_{i}}}} \text { if } n T+\theta<t \leq(n+1) T
\end{array}\right.
$$

Therefore, the junction temperature variation in steady-state conditions will be,

$$
\begin{aligned}
& \Delta \theta_{j \mathrm{C} \infty}=\left(P_{F M}-\frac{\theta}{T} P_{F M}\right) \sum_{i=1}^{k} r_{i}-P_{F M} \sum_{i=1}^{k} r_{i} e^{-\frac{\theta}{T_{i}}} \frac{1-e^{-\frac{T-\vartheta}{T_{i}}}}{1-e^{-\frac{T}{T_{i}}}}=P_{F M} \sum_{i=1}^{k} r_{i}\left[1-\frac{\theta}{T}-e^{-\frac{\theta}{T_{i}}} \frac{1-e^{-\frac{T-\vartheta}{T_{i}}}}{1-e^{-\frac{T}{T_{i}}}}\right]= \\
& =P_{F M} \sum_{i=1}^{k} r_{i}\left(\frac{1-e^{-\frac{\vartheta}{T_{i}}}}{1-e^{-\frac{T}{T_{i}}}}-\frac{\theta}{T}\right.
\end{aligned}
$$

\subsection{Increasing triangle pulse series input power}

A series of increasing triangle pulses is shown in Fig. 3 and the equation which describes this series is given in (7).

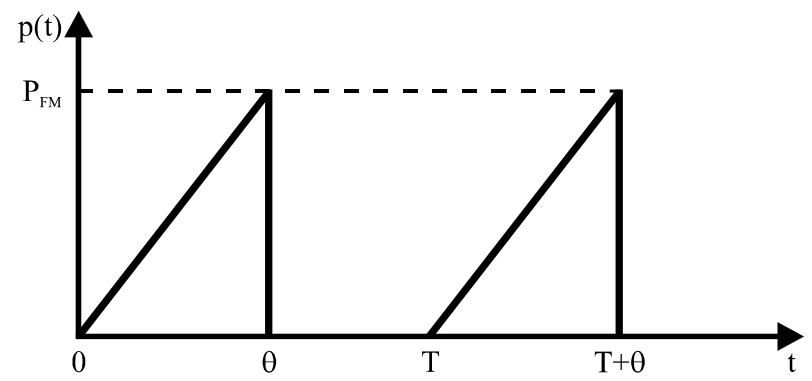

Fig. 3. Increasing triangle pulse series input power 


$$
P(t)=\left\{\begin{array}{lll}
t \frac{P_{F M}}{\theta} & \text { if } & n T \leq t \leq \theta+n T, \\
0 & \text { if } & \theta+n T<t \leq(n+1) T
\end{array}\right.
$$

In the case when $n \rightarrow \infty$, the thermal response will be,

$$
\Delta \theta_{j C \infty}(t)=\left\{\begin{array}{l}
\frac{P_{F M}}{\theta} \sum_{i=1}^{k} r_{i}\left\{t-T_{i}\left[\begin{array}{c}
1-\frac{1-\left(1-\frac{\theta}{T_{i}}\right) e^{-\frac{T-\theta}{T_{i}}}}{1-e^{-\frac{T}{T_{i}}}} e^{-\frac{t}{T_{i}}}
\end{array}\right]\right\} \quad \text { if } n T \leq t \leq \theta+n T, \\
\frac{P_{F M}}{\theta} \sum_{i=1}^{k} r_{i} T_{i} \frac{\frac{\theta}{T_{i}}+e^{-\frac{\theta}{T_{i}}}-1}{1-e^{-\frac{T}{T_{i}}} e^{-\frac{t-\theta}{T_{i}}}} \text { if } \quad \theta+n T<t \leq(n+1) T
\end{array}\right.
$$

\subsection{Decreasing triangle pulse series input power}

Figure 4 shows a decreasing triangle pulse series with its equation (9).

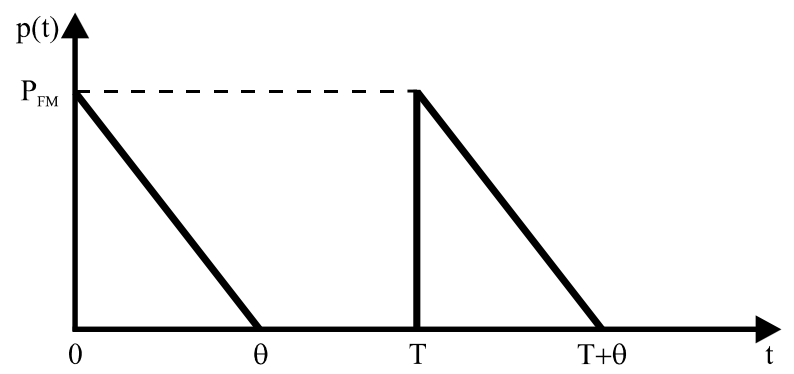

Fig. 4. Decreasing triangle pulse series input power

$$
P(t)= \begin{cases}1-t \frac{P_{F M}}{\theta} \quad \text { if } \quad n T \leq t \leq \theta+n T, \\ 0 \quad \text { if } \quad \theta+n T<t \leq(n+1) T\end{cases}
$$

At limit, when $n \rightarrow \infty$, the thermal response will be:

$$
\Delta \theta_{j C \infty}(t)=\left\{\begin{array}{l}
\frac{P_{F M}}{\theta} \sum_{i=1}^{k} r_{i}\left\{(\theta-t)-T_{i}\left[\begin{array}{c}
1+\frac{\theta}{T_{i}}-e^{-\frac{T-\theta}{T_{i}}} \\
-1-e^{-\frac{T}{T_{i}}} e^{-\frac{t}{T_{i}}}
\end{array}\right]\right\} \quad \text { if } n T \leq t \leq \theta+n T, \\
\frac{P_{F M}}{\theta} \sum_{i=1}^{k} r_{i} T_{i} \frac{1-\left(1+\frac{\theta}{T_{i}}\right) e^{-\frac{\theta}{T_{i}}}}{1-e^{-\frac{T}{T_{i}}}} \text { if } \quad \theta+n T<t \leq(n+1) T
\end{array}\right.
$$




\subsection{Triangle pulse series input power}

A series of triangle input power is shown in Fig. 5. The equation which describes this kind of series is given in (11).

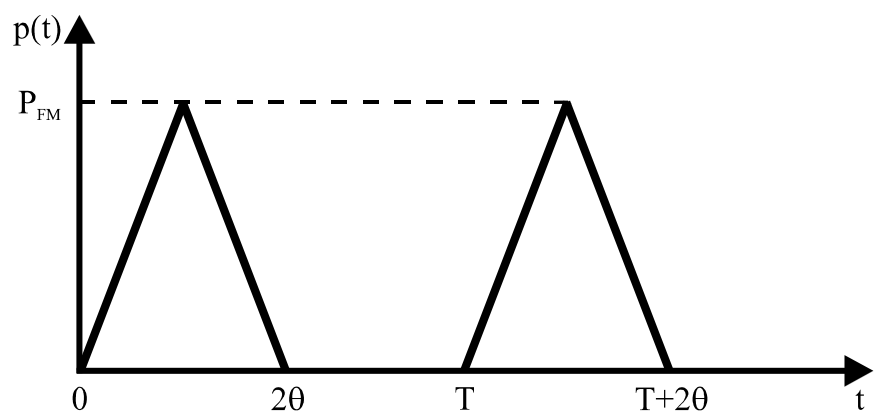

Fig. 5. Triangle pulse series input power.

$$
P(t)=\left\{\begin{array}{llc}
t \frac{P_{F M}}{\theta} & \text { if } \quad n T \leq t \leq \theta+n T, \\
\left(2-\frac{t}{\theta}\right) P_{F M} & \text { if } \quad \theta+n T<t \leq 2 \theta+n T, \\
0 & \text { if } & 2 \theta+n T<t \leq(n+1) T
\end{array}\right.
$$

For junction temperature computation when $n \rightarrow \infty$, the following relation will be used:

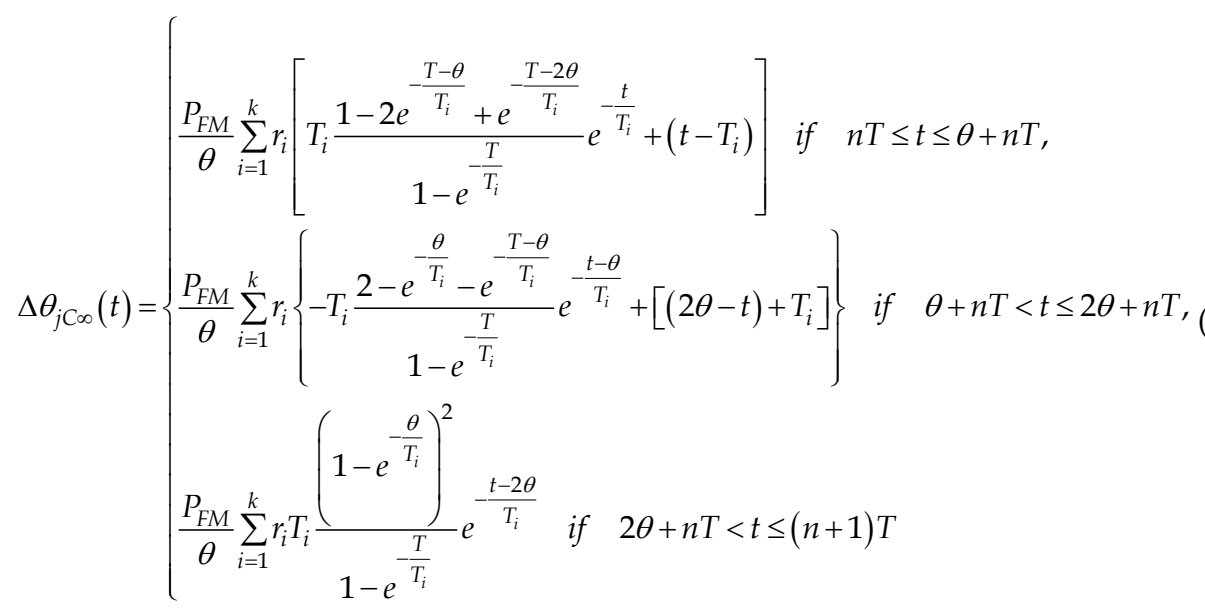

\subsection{Trapezoidal pulse series input power}

Figure 6 shows a trapezoidal pulse series with the equation from (13). 


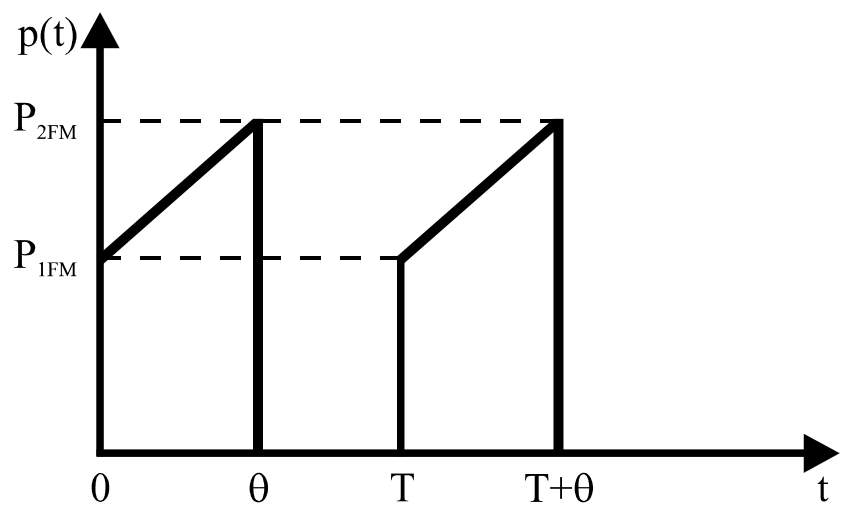

Fig. 6. Trapezoidal pulse series input power

$$
P(t)= \begin{cases}P_{1 F M}+\left(P_{2 F M}-P_{1 F M}\right) \frac{t}{\theta} & \text { if } \quad n T \leq t \leq \theta+n T, \\ 0 & \text { if } \quad \theta+n T<t \leq(n+1) T\end{cases}
$$

At limit, $n \rightarrow \infty$, the thermal response is given by,

$$
\Delta \theta_{j C_{\infty}}(t)=\left\{\begin{array}{l}
\frac{1}{\theta} \sum_{i=1}^{k} r_{i}\left[\begin{array}{c}
T_{i} \frac{F_{P_{1} P_{2}}}{1-e^{-\frac{T}{T_{i}}}} e^{-\frac{t}{T_{i}}}+P_{1 F M}+\frac{P_{2 F M}-P_{1 F M}}{\theta}\left(t-T_{i}\right) \\
\frac{1}{\theta} \sum_{i=1}^{k} r_{i} T_{i} \frac{G_{P_{1} P_{2}}}{1-e^{-\frac{T}{T_{i}}}} e^{-\frac{t-\theta}{T_{i}}} \quad \text { if } \quad \theta+n T<t \leq(n+1) T
\end{array}\right] \text { if } n T \leq t \leq \theta+n T,
\end{array}\right.
$$

where:

$$
\begin{aligned}
& F_{P_{1} P_{2}}=P_{2 F M}-P_{1 F M}\left(1+\frac{\theta}{T_{i}}\right)+\left[P_{1 F M}-P_{2 F M}\left(1-\frac{\theta}{T_{i}}\right)\right] e^{-\frac{T-\theta}{T_{i}}}, \\
& G_{P_{1} P_{2}}=P_{1 F M}-P_{2 F M}\left(1-\frac{\theta}{T_{i}}\right)+\left[P_{2 F M}-P_{1 F M}\left(1+\frac{\theta}{T_{i}}\right)\right] e^{-\frac{\theta}{T_{i}}}
\end{aligned}
$$

\subsection{Partial sinusoidal pulse series input power}

A partial sinusoidal pulse series waveform is shown in Fig. 7. The equation which describes this kind of waveform is given by (16). 


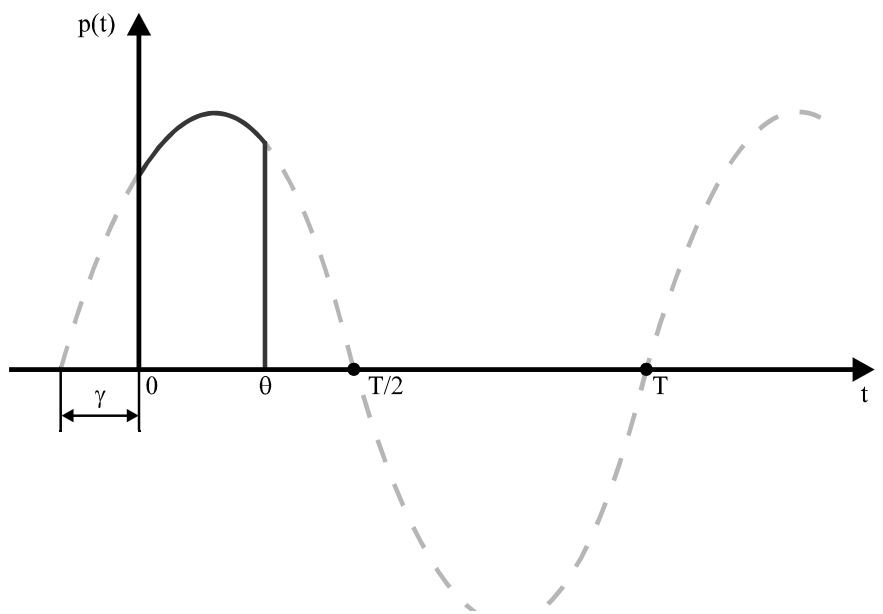

Fig. 7. Partial sinusoidal pulse series input power

$$
P(t)=\left\{\begin{array}{l}
P_{F M} \sin (\omega t+\gamma) \text { if } n T \leq t \leq \theta+n T, \\
0 \quad \text { if } \theta+n T<t \leq(n+1) T
\end{array}\right.
$$

In order to establish the junction temperature when $n \rightarrow \infty$, it will use the relation,

$$
\Delta \theta_{j C \infty}(t)=\left\{\begin{array}{l}
P_{F M}\left\{Z \sin (\omega t+\gamma-\delta)-\sum_{i=1}^{k} r_{i}\left[\sin \left(\gamma-\varphi_{i}\right)-\sin \left(\gamma-\varphi_{i}+\omega \theta\right) e^{-\frac{T-\theta}{T_{i}}}\right] \frac{e^{-\frac{t}{T_{i}}}}{\left(1-e^{-\frac{T}{T_{i}}}\right) \sqrt{1+\left(\omega T_{i}\right)^{2}}}\right. \\
\quad \text { if } n T \leq t \leq \theta+n T, \\
P_{F M} \sum_{i=1}^{k} r_{i}\left[\sin \left(\omega \theta+\gamma-\varphi_{i}\right)-\sin \left(\gamma-\varphi_{i}\right) e^{-\frac{\theta}{T_{i}}}\right] \frac{e^{-\frac{t-\theta}{T_{i}}}}{\left(1-e^{-\frac{T}{T_{i}}}\right) \sqrt{1+\left(\omega T_{i}\right)^{2}}} \\
\quad \text { if } \quad \theta+n T<t \leq(n+1) T
\end{array}\right\}
$$

where:

$$
\operatorname{ctg} \phi_{i}=\frac{1}{\omega T_{i}} ; \quad Z^{2}=\sum_{i=1}^{k}\left(r_{i} \cos ^{2} \varphi_{i}\right)^{2}+\sum_{i=1}^{k}\left(\frac{r_{i}}{2} \sin 2 \varphi_{i}\right)^{2} ; \quad \operatorname{tg} \delta=\frac{\sum_{i=1}^{k} \frac{r_{i}}{2} \sin 2 \varphi_{i}}{\sum_{i=1}^{k} r_{i} \cos ^{2} \varphi_{i}}
$$

Extremely short overloads of the type that occur under surge or fault conditions, are limited to a few cycles in duration. Here the junction temperature exceeds its maximum rating and all operational parameters are severely affected. However the low transient thermal 
impedance offered by the device in this region of operation, is often sufficient to handle the power that is dissipated.

A transient thermal calculation even using the relation (2), is very complex and difficult to do. Hence, a more exactly and efficiently thermal calculation of power semiconductors at different types of input power specific to power converters, can be done with the help of PSpice software and/or 3D finite element analysis.

\section{Thermal simulations of power semiconductors from rectifiers}

Further on, it presents the waveforms of input powers and junction temperatures of power semiconductors, diodes and thyristors, from different types of single-phase bridge rectifiers. Also, temperature waveforms in the case of steady state thermal conditions, are shown. Using PSpice software, a parametric simulation which highlights the influence of some parameter values upon temperature waveforms has been done.

On ordinate axis, the measurement unit in the case of input power waveforms, is the watt, and in the case of temperatures, the measurement unit is the ${ }^{0} \mathrm{C}$, unlike the volt one that appears on graphics. This apparent unconcordance between measurement units is because thermal phenomena had been simulated using electrical circuit analogy. The notations on the graphics $P_{1}, P_{2}$ and $P_{3}$ mean input powers and $T_{1}, T_{2}$ and $T_{3}$ temperatures, respectively.

\subsection{Single-phase uncontrolled bridge rectifier}

The waveforms of the input powers and junction temperatures of power diodes from the structure of a single-phase uncontrolled bridge rectifier are shown in the below diagrams.

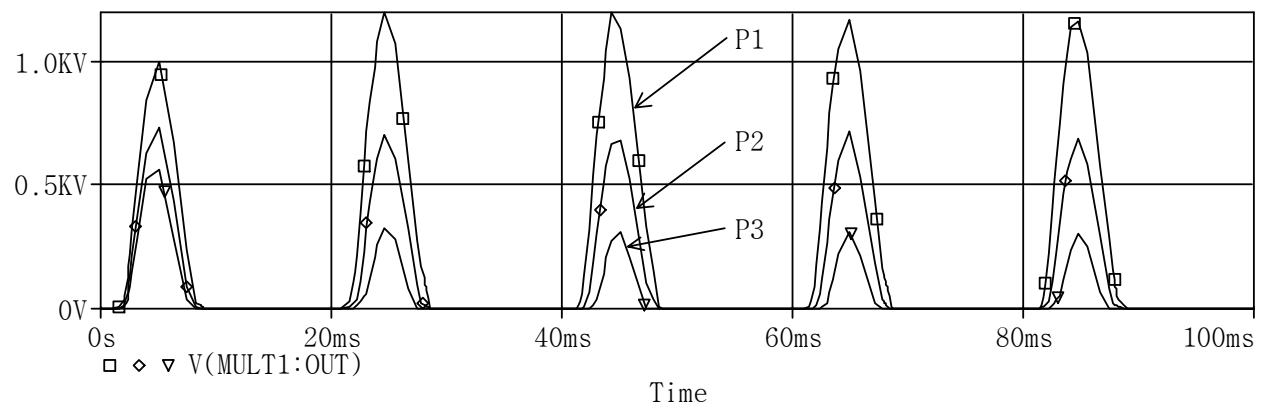

Fig. 8. Input power waveforms at load resistance variation with 10, 20, $50 \Omega$

From the above graphics, Fig. 8 , the input power variation $P_{1}, P_{2}$ and $P_{3}$ with the load resistance values can be noticed. The increase of load values leads to small input power values, and finally, to the decrease of junction temperature magnitudes, $T_{1}, T_{2}$ and $T_{3}$, Fig. 9 , and also to the decrease of temperature variations. In the case of quasi-steady state thermal conditions, Fig. 10, there are a clearly difference between temperatures waveforms variation. Also, the time variations of temperature values are insignificantly. The maximum value of $\mathrm{T}_{1}$ temperature, Fig. 10, outruns the maximum admissible value for power semiconductor junction, about $125^{\circ} \mathrm{C}$. Therefore, it requires an adequate protection for the power diode or increasing of load resistance. 


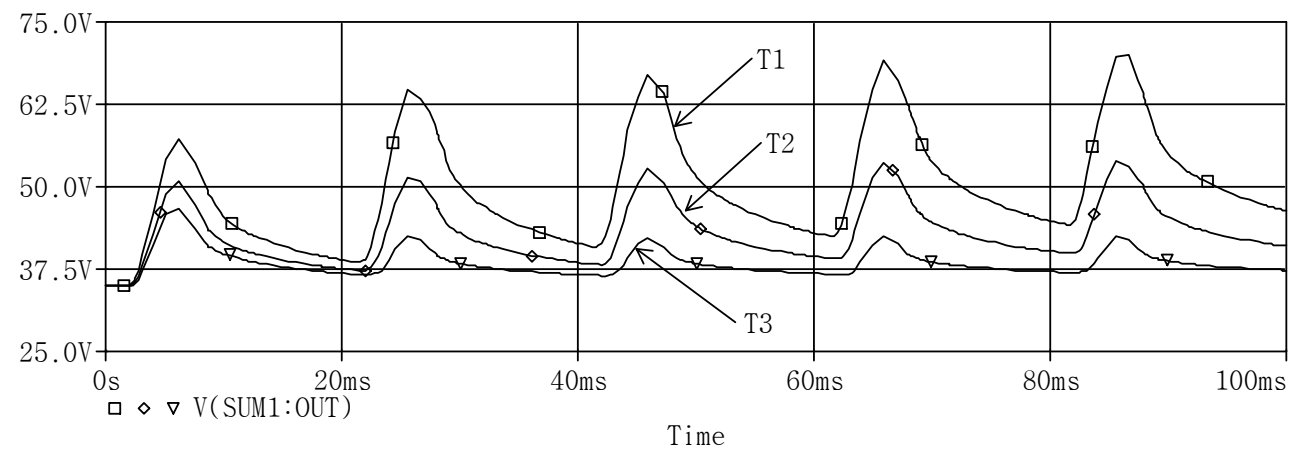

Fig. 9. Temperature waveforms of thermal transient conditions at load variation with 10, 20, $50 \Omega$

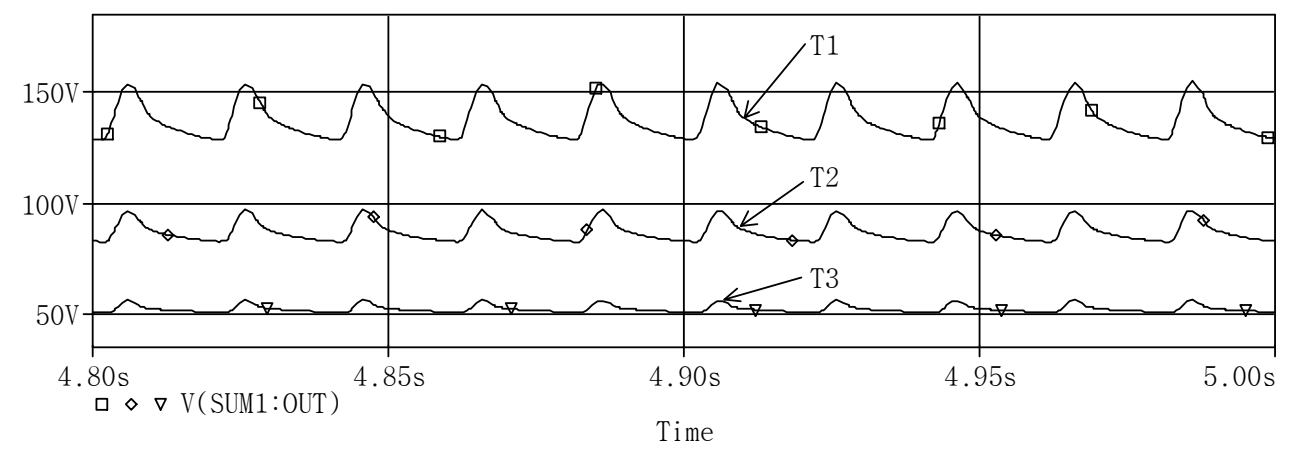

Fig. 10. Temperature waveforms of quasi-steady state thermal conditions at load variation with $10,20,50 \Omega$

\subsection{Single-phase semicontrolled bridge rectifier}

In the case of a single-phase semicontrolled bridge rectifier made with power diodes and thyristors, the time variations of input powers and temperatures are presented below.

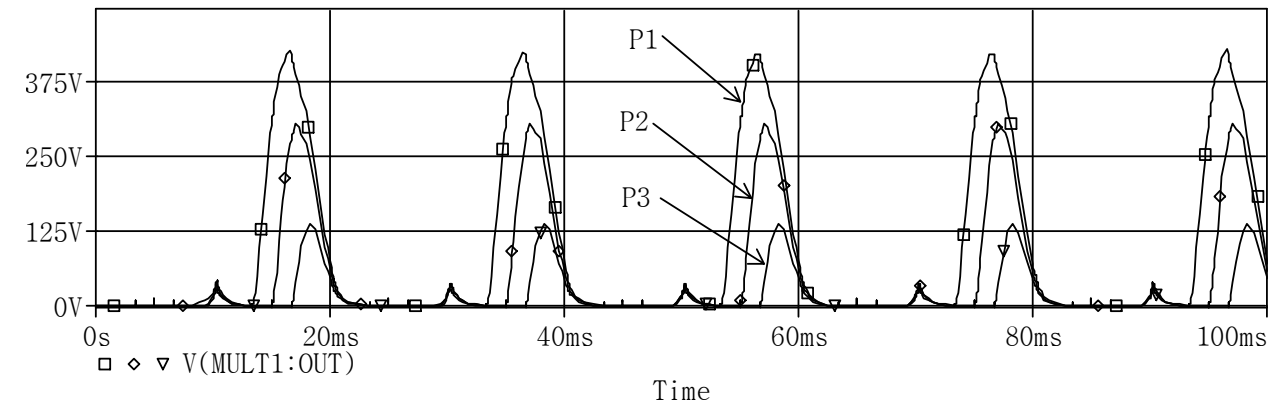

Fig. 11. Input power waveforms at firing angle variation with 60, 90, $1200 \mathrm{el}$. 


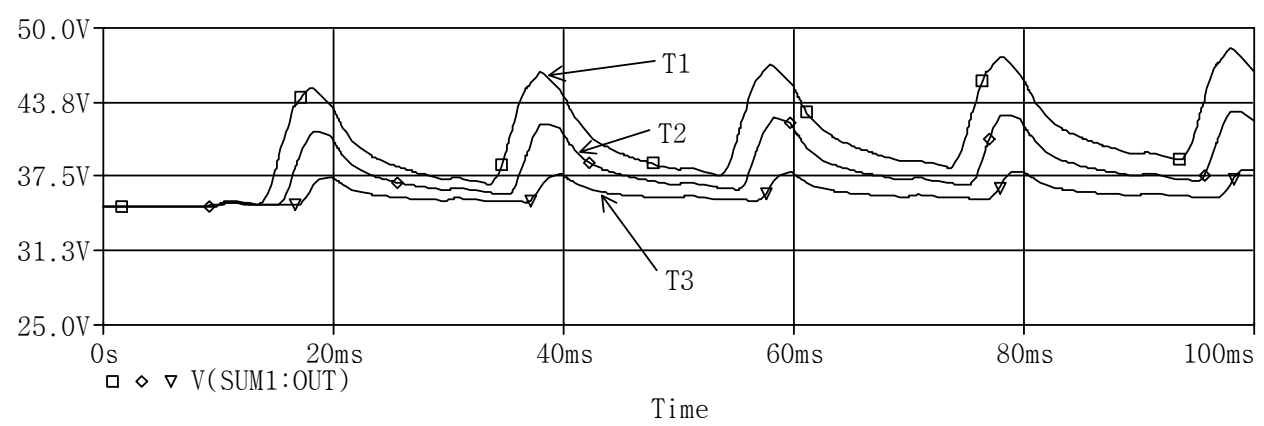

Fig. 12. Temperature waveforms of thermal transient conditions at firing angle variation with $60,90,120^{\circ} \mathrm{el}$.

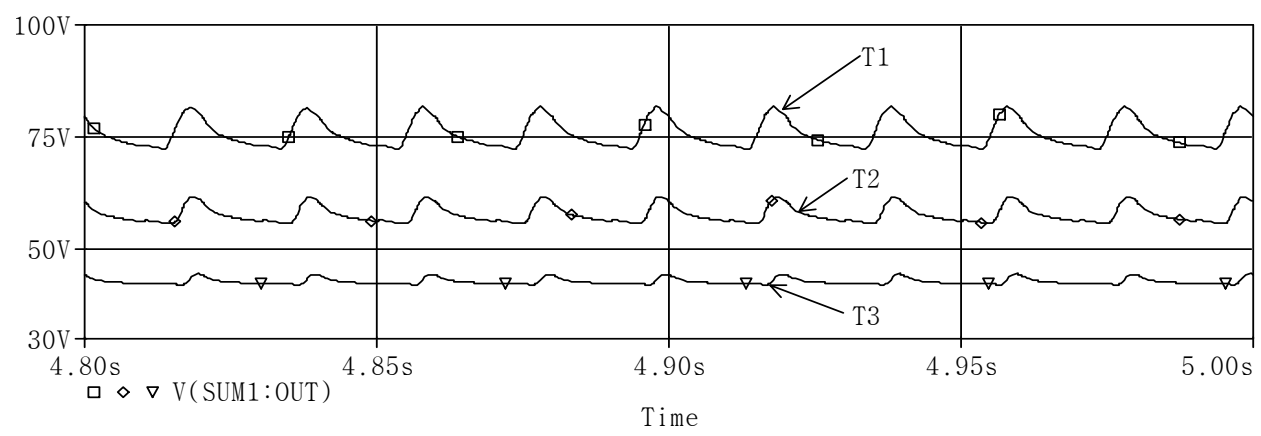

Fig. 13. Temperature waveforms of quasi-steady state thermal conditions at firing angle variation with $60,90,120^{\circ} \mathrm{el}$.

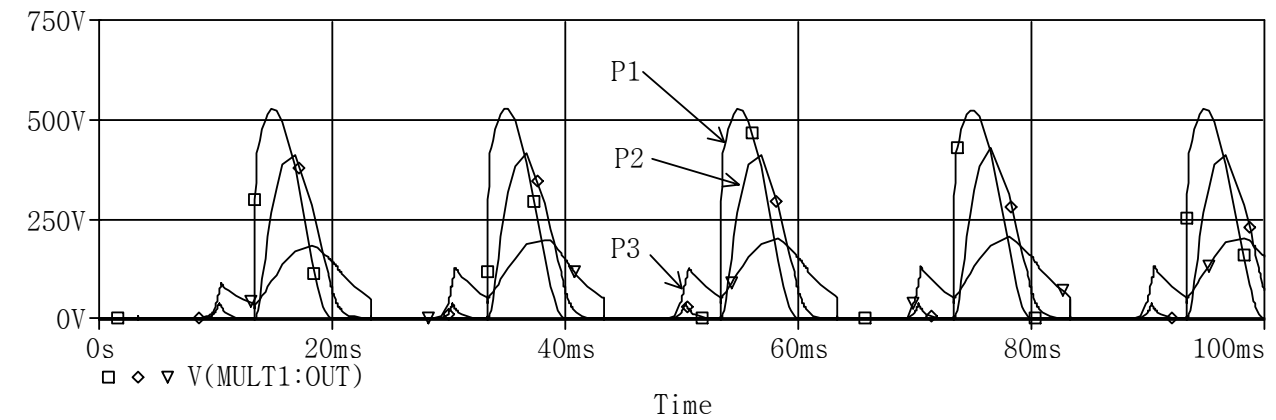

Fig. 14. Input power waveforms at load inductance variation with $0.1,10,50 \mathrm{mH}$

It has been done a parametric simulation both at firing angle variation of thyristors from semicontrolled bridge rectifier, Fig. 11...13, and at load inductance variation, Fig. 14...16. As in previous situation, the case with uncontrolled bridge rectifier, the variation of input power values depend on load inductance, Fig. 14. The increase of inductance value, from 
$0.1 \mathrm{mH}$ to $50 \mathrm{mH}$, leads not only to input power decreasing, $\mathrm{P}_{3}<\mathrm{P}_{2}<\mathrm{P}_{1}$, but also its shape changing. The same thing can be observed at firing angle variation, Fig. 11...13. Hence, the increase of the firing angle from 60 to $120^{\circ}$ el., leads to decrease of input power values $\mathrm{P}_{3}<$ $\mathrm{P}_{2}<\mathrm{P}_{1}$. Also, the increase of load inductance leads to decrease of temperature values, $\mathrm{T}_{3}<\mathrm{T}_{2}$ $<\mathrm{T}_{1}$, as shown in Fig. 15 and Fig. 16. The steady state thermal conditions allow to highlight the temperature differences in the case of firing angle variation, $\mathrm{T}_{3}<\mathrm{T}_{2}<\mathrm{T}_{1}$, Fig. 13, and load variation, $\mathrm{T}_{3}<\mathrm{T}_{2}<\mathrm{T}_{1}$, Fig. 16 .

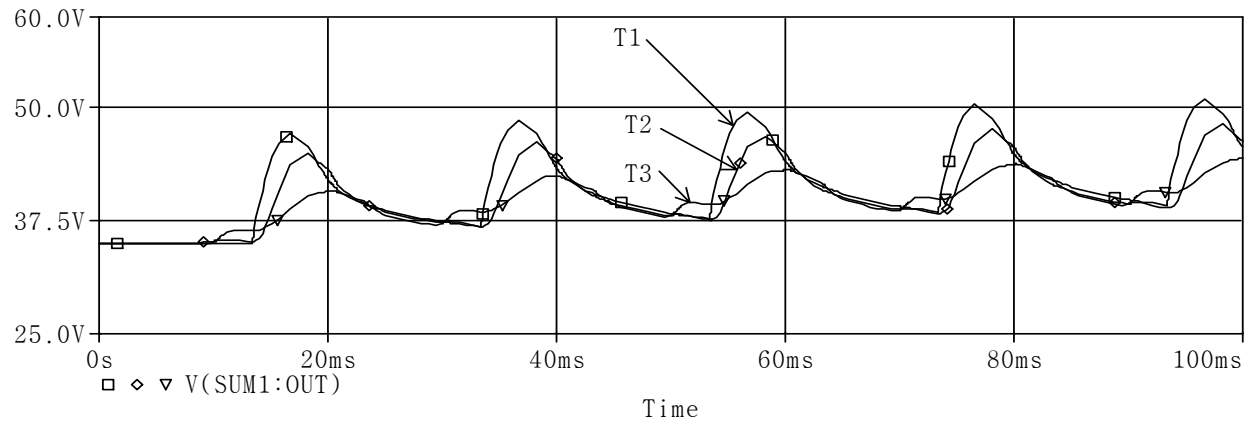

Fig. 15. Temperature waveforms of thermal transient conditions at load inductance variation with $0.1,10,50 \mathrm{mH}$

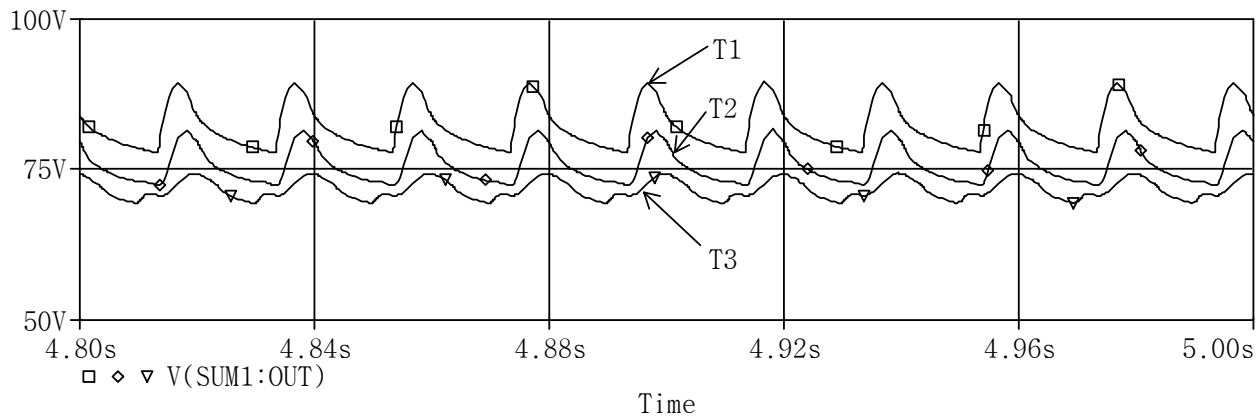

Fig. 16. Temperature waveforms of quasi-steady state thermal conditions at load inductance variation with $0.1,10,50 \mathrm{mH}$

\subsection{Single-phase controlled bridge rectifier}

Next diagrams present input power variation and temperature values in the case of a singlephase controlled bridge rectifier made with power thyristors.

As in the case of single-phase semicontrolled bridge rectifier, a parametric simulation for firing angle variation has been done. It can be noticed that increasing of firing angle leads to input power and temperature decrease, Fig. 17 and Fig. 18. The quasi-steady state thermal conditions highlight the differences between temperature values and their variations, Fig. 19. In order to validate the thermal simulations some experimental tests have been done. It was recorded the temperature rise on the case of the thyristors used for semi-controlled 
power rectifier. The temperatures have been measured using proper iron-constantan thermocouples fixed on the case of power semiconductor devices. The measurements have been done both for the firing angle values of 60, 90 and $120^{\circ}$ el., and load inductance values of $0.1,10$ and $50 \mathrm{mH}$. The results are shown in Fig. 20 and Fig. 21.

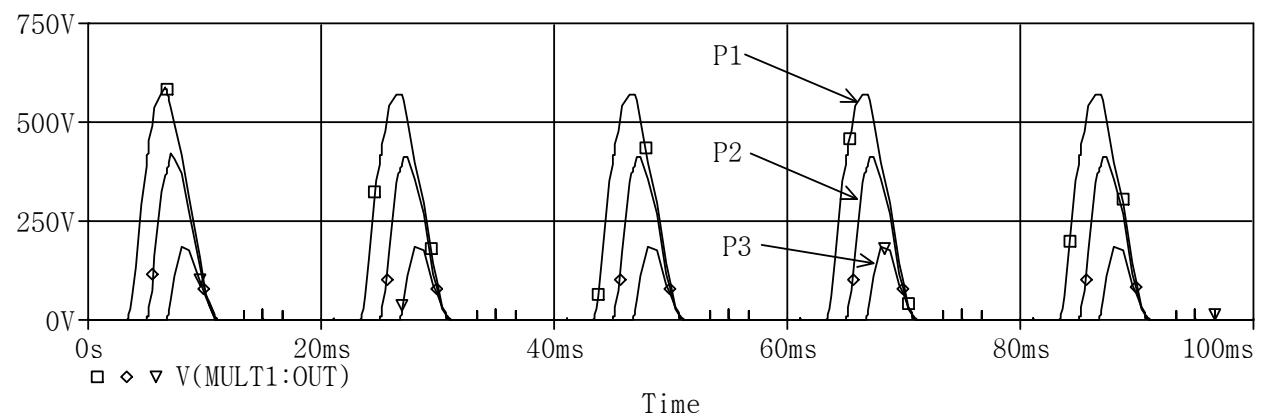

Fig. 17. Input power waveforms at firing angle variation with $60,90,120^{0} \mathrm{el}$.

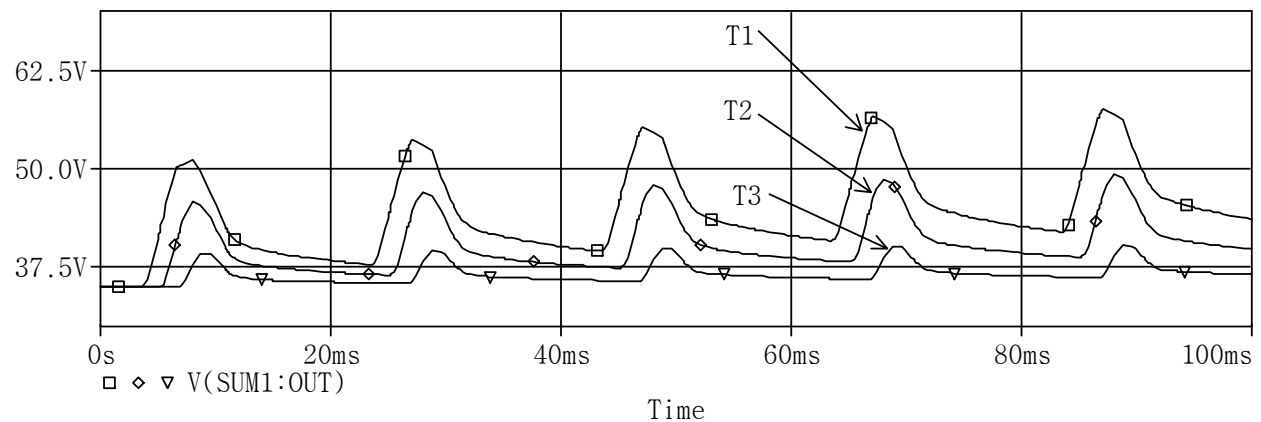

Fig. 18. Temperature waveforms of thermal transient conditions at firing angle variation with $60,90,120^{\circ} \mathrm{el}$.

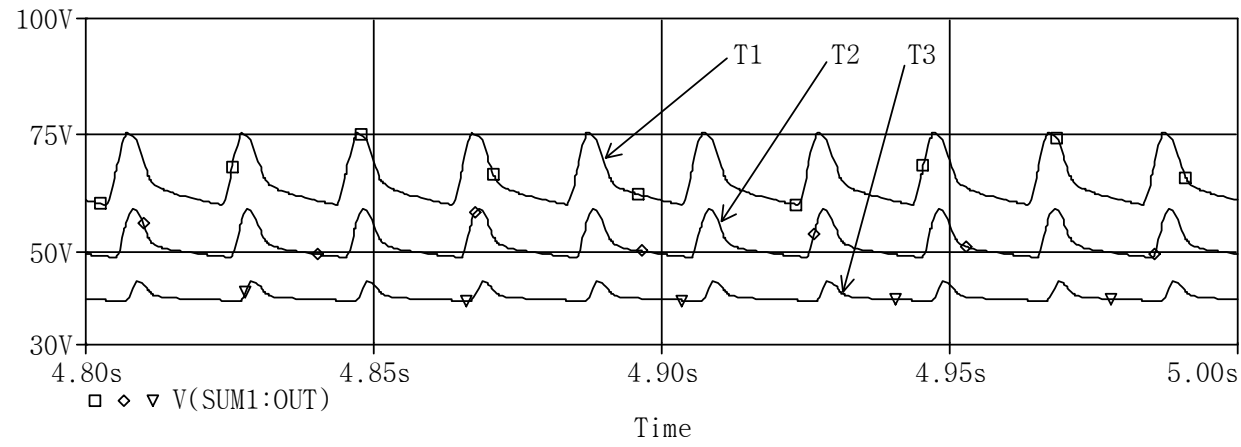

Fig. 19. Temperature waveforms of quasi-steady state thermal conditions at firing angle variation with $60,90,120^{\circ} \mathrm{el}$. 


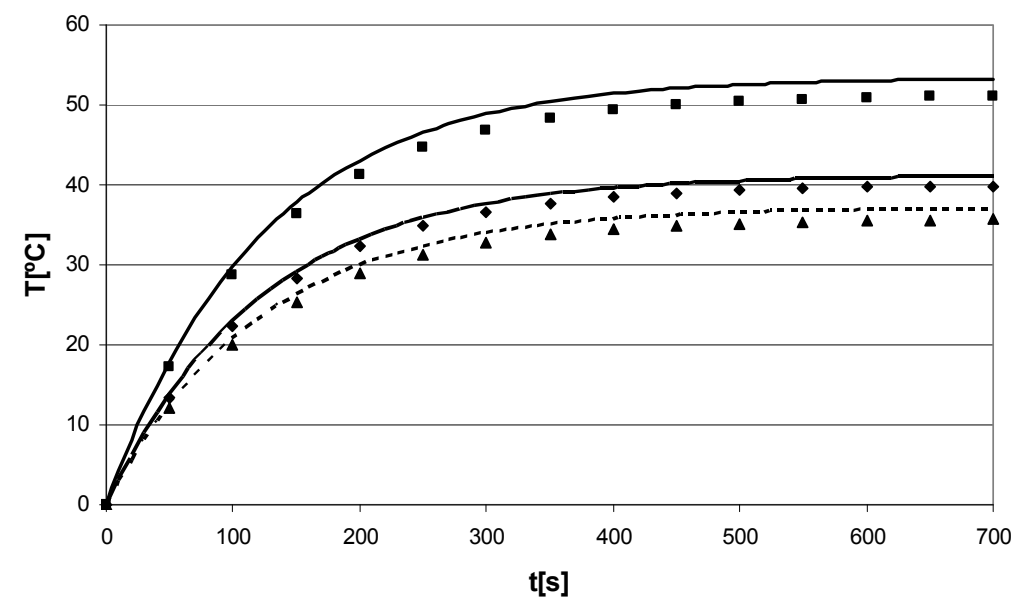

60el.sim - - -90el.sim - - - .120el.sim

- 60el.exp

90el.exp $\Delta \quad$ 120el.exp

Fig. 20. Comparison between simulation and experimental temperature rise of the case at firing angle variation

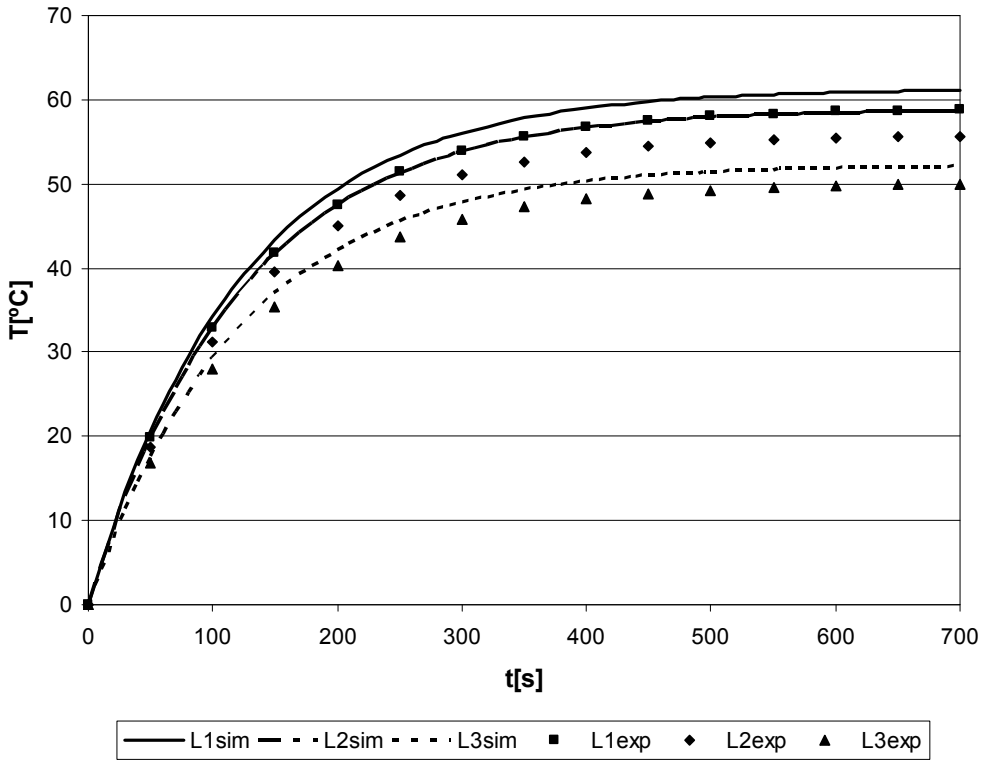

Fig. 21. Comparison between simulation and experimental temperature rise of the case at inductance load variation

In both cases, at firing angle and load inductance variation, it ca be noticed closer values between simulation results and measurements. Of course, there are different temperature 
values resulted from experimental tests (60el.exp, 90el.exp and 120el.exp from Fig. 20 and L1exp, L2exp, L3exp as shown in Fig. 21) with respect to simulations (60el.sim, 90el.sim and 120el.sim from Fig. 20 and L1sim, L2sim, L3sim as in Fig. 21), because of measurement errors, thermal model simplifications and mounting test conditions. Anyway, the maximum difference between experimental and simulation results is less than $3^{\circ} \mathrm{C}$.

\subsection{D thermal modelling and simulations of power semiconductors}

During former work, (Chung, 1999; Allard et al., 2005), because of limited computer capabilities, the authors had to concentrate on partial problems or on parts of power semiconductors geometry. The progress in computer technology enables the modelling and simulation of more and more complex structures in less time. It has therefore been the aim of this work to develop a 3D model of a power thyristor as main component part from power semiconductor converters.

The starting point is the power balance equation for each volume element $d V$, in the integral formulation:

$$
\iiint \frac{j^{2}}{\sigma} d V=\iiint \rho c \frac{\partial T}{\partial t} d V-\iiint \operatorname{div}(\lambda \cdot \operatorname{grad} T) d V
$$

where:

$\mathrm{T}$ means the temperature of element $\left[{ }^{\circ} \mathrm{C}\right]$;

$\mathrm{j}$ - current density $\left[\mathrm{A} / \mathrm{m}^{2}\right]$;

$\sigma$ - electrical conductivity $[1 / \Omega \mathrm{m}]$;

$\rho$ - material density $\left[\mathrm{kg} / \mathrm{m}^{3}\right]$;

$\mathrm{c}$ - specific heat $\left[\mathrm{J} / \mathrm{kg}^{\circ} \mathrm{C}\right]$;

$\lambda$ - thermal conductivity $\left[\mathrm{W} / \mathrm{m}^{\circ} \mathrm{C}\right]$.

The left term of before equation (it exists only in the device conductor elements), denotes the heating power from the current flow. It is in balance with the heat stored by temporal change of temperature, and the power removed from the element by thermal conduction. For the steady state temperature calculation, the heat storage term is zero, and the equation (19) becomes,

$$
\iiint \frac{j^{2}}{\sigma} d V=-\iiint \operatorname{div}(\lambda \cdot \operatorname{grad} T) d V
$$

Taking one's stand on the above thermal equations, first of all a 3D model for a power thyristor has been developed using a specific software, the Pro-ENGINEER, an integrated thermal design tool for all type of accurate thermal analysis on devices.

It has been considered an application which includes a bidirectional bridge equiped with power thyristors type AT505, with the average direct current of $430 \mathrm{~A}$ and an internal resistance of $0.68 \mathrm{~m} \Omega$. The current which flows through the converter branches is about $315 \mathrm{~A}$. This value allows computing the power loss for each tyristor, which results in $67.47 \mathrm{~W}$. The material properties of every component part of the thyristor are described in the Table 2 and the 3D thermal models of the thyristor with its main component parts and together with its heatsinks for both sides cooling are shown in Fig. 22, respectively, Fig. 23. 


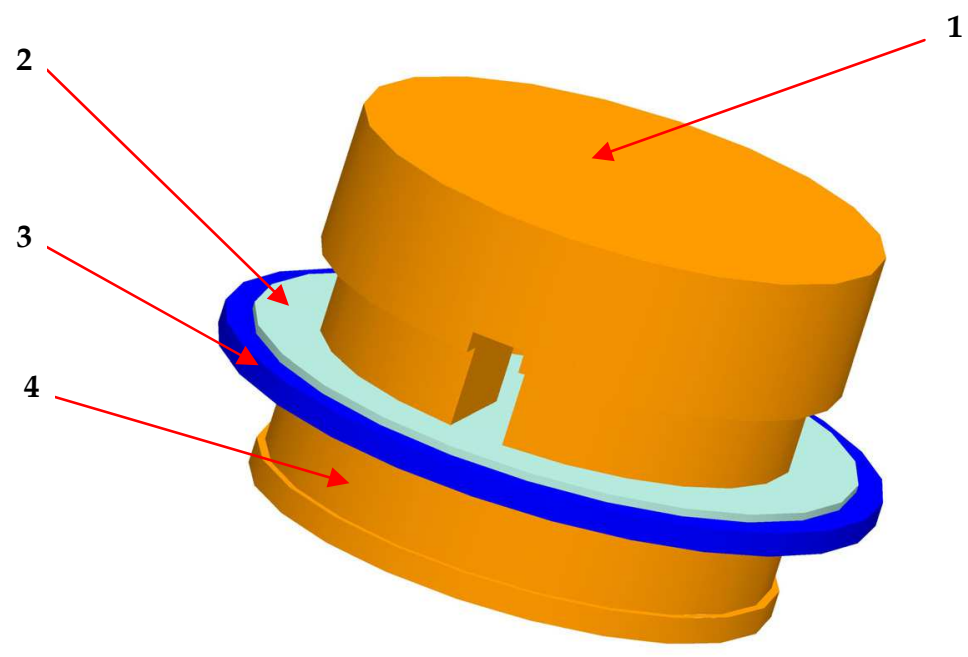

Fig. 22. Thermal model of the thyristor (1 - cathode copper pole; 2 - silicon chip; 3 - molybdenum disc; 4 - anode copper)

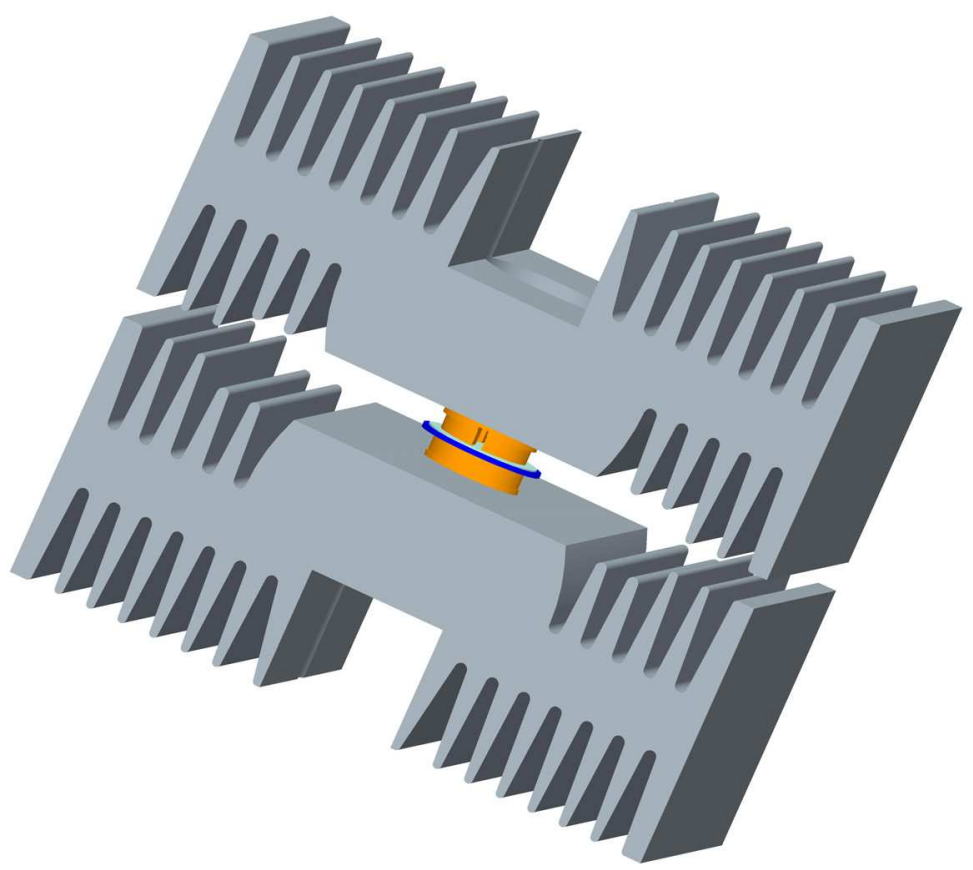

Fig. 23. Thermal model of the assembly thyristor - heatsinks 
The thermal model of the power semiconductor has been obtained by including all the piece part that is directly involved in the thermal exchange phenomenon, which is: anode copper pole, molybdenum disc, silicon chip, cathode copper pole, Fig. 22. The device ceramic enclosure has not been included in the model since the total heat flowing trough it is by far less important than the heat flowing through the copper poles. All the mechanical details which are not important for the heat transfer within the thyristor and from the thyristor to the external environment (e.g. the centering hole on the poles) have been suppressed.

\begin{tabular}{|c|c|c|c|c|}
\hline \multirow{2}{*}{ Parameter } & \multicolumn{4}{|c|}{ Material } \\
\cline { 2 - 5 } & Copper & Silicon & Molybdenum & Aluminium \\
\hline$\rho\left(\mathrm{kg} / \mathrm{m}^{3}\right)$ & 8900 & 2330 & 10220 & 2700 \\
\hline $\mathrm{c}\left(\mathrm{J} / \mathrm{kg}^{\circ} \mathrm{C}\right)$ & 387 & 702 & 255 & 900 \\
\hline$\lambda\left(\mathrm{W} / \mathrm{m}^{\circ} \mathrm{C}\right)$ & 385 & 124 & 138 & 200 \\
\hline
\end{tabular}

Table 2. Material Data and Coefficients at $20^{\circ} \mathrm{C}$

The heat load has been applied on the active surface of the silicon of power semiconductor. It is a uniform spatial distribution on this surface. The ambient temperature was about $25^{\circ} \mathrm{C}$. From experimental tests it was computed the convection coefficient value, $k_{t}=$ $14.24 \mathrm{~W} / \mathrm{m}^{2}{ }^{\circ} \mathrm{C}$ for this type of heatsinks for thyristor cooling. Hence, it was considered the convection condition like boundary condition for the outer boundaries such as heatsinks. The convection coefficient has been applied on surfaces of heatsinks with a uniform spatial variation and a bulk temperature of $25^{\circ} \mathrm{C}$. The mesh of this $3 \mathrm{D}$ power semiconductor thermal model has been done using tetrahedron solids element types with the following allowable angle limits (degrees): maximum edge: 175; minimum edge: 5; maximum face: 175; minimum face: 5. The maximum aspect ratio was 30 and the maximum edge turn (degrees): 95. Also, the geometry tolerance had the following values: minimum edge length: 0.0001; minimum surface dimension: 0.0001; minimum cusp angle: 0.86; merge tolerance: 0.0001. The single pass adaptive convergence method to solve the thermal steady-state simulation has been used.

Then, it has been made some steady-state thermal simulations for the power semiconductor. For all thermal simulations a 3D finite elements Pro-MECHANICA software has been used. The temperature distribution of the tyristor which uses double cooling, both on anode and cathode, is shown in the pictures below, Fig. 24 and Fig. 25. The maximum temperature for the power semiconductor is on the silicon area and is about $70.49^{\circ} \mathrm{C}$ and the minimum of $47.97^{\circ} \mathrm{C}$ is on the heatsink surfaces.

Further on, the thermal transient simulations have been done in order to compute the transient thermal impedance for power thyristor. The result is shown in Fig. 26.

From thermal transient simulations we obtain the maximum temperature time variation and the minimum temperature time variation. From the difference between maximum temperature time variation and ambient temperature divided to total thermal load it gets the thermal transient impedance. Dividing the thermal transient impedance to the thermal resistance, the normalised thermal transient impedance can be obtained. This is a thermal quantity which reflects the power semiconductor thermal behaviour during transient conditions.

To understand and to optimize the operating mechanisms of power semiconductor converters, the thermal behaviour of the power device itself and their application is of major interest. Having the opportunity to simulate the thermal processes at the power 

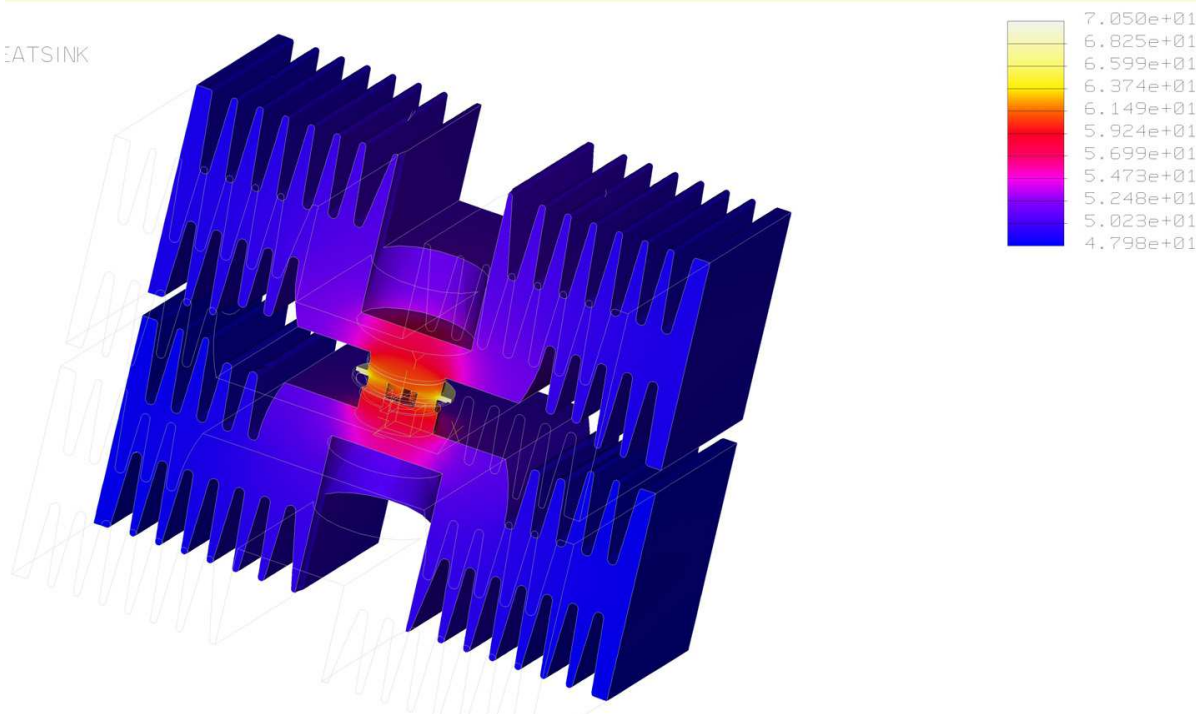

Fig. 24. Temperature distribution through the thyristor mounted between heatsinks at $50 \%$ cross section, yz plane
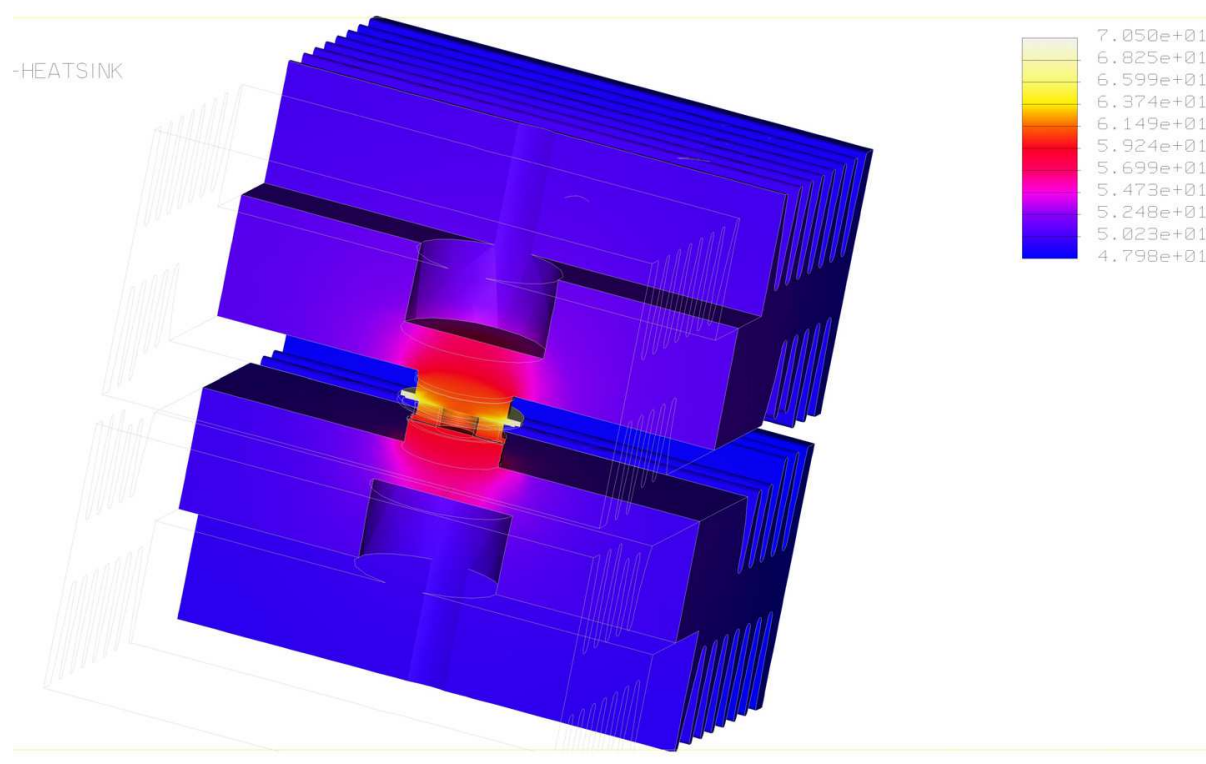

Fig. 25. Temperature distribution through the thyristor mounted between heatsinks at $50 \%$ cross section, xz plane 


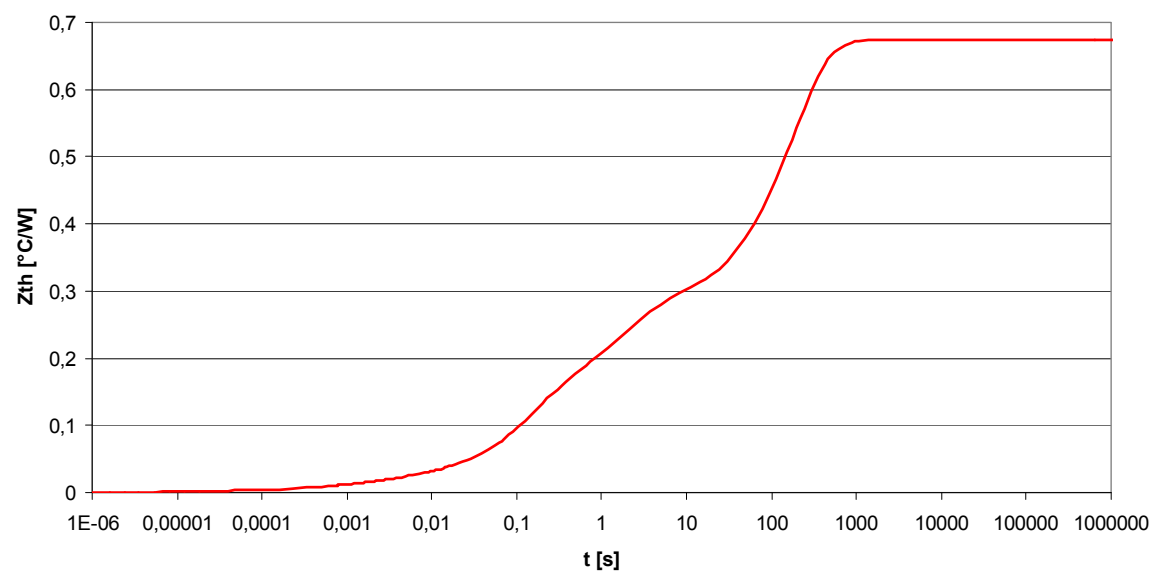

Fig. 26. Transient thermal impedance of the thyristor

semiconductor junction dependent on the power device design enables new features for the optimization of power semiconductor converters. This has a great impact to the development and test costs of new power converters.

\section{Conclusion}

From all previous thermal modelling, simulation and experimental tests, the following conclusions about transient thermal evolution of power semiconductor devices can be outlined:

- the shape of input power and temperatures evolution depend on load type, its value and firing angle in the case of power semicontrolled rectifiers;

- increasing of load inductance value leads to decrease of input power and temperature values;

- in the case of steady state thermal conditions, the temperature variation is not so important at big values of load inductance and firing angle;

- at big values of firing angle it can be noticed a decrease of input power values and temperatures;

- there is a good correlation between simulation results and experimental tests;

- because of very complex thermal phenomenon the analysis of power semiconductor device thermal field can be done using a specific 3D finite element method software; therefore, the temperature values anywhere inside or on the power semiconductor assembly can be computed both for steady-state or transient conditions;

- using the 3D simulation software there is the possibility to improve the power semiconductor converters design and also to get new solutions for a better thermal behaviour of power semiconductor devices.

Extending the model with thermal models for the specific applications enables the user of power semiconductors to choose the right ratings and to evaluate critical load cycles and to identify potential overload capacities for a dynamic grid loading. It was shown that the described thermal network simulation has a high potential for a variety of different applications:

- development support; 
- identifying user risks;

- $\quad$ evaluating the right rated current;

- evaluating overload capacity without destructive failure of the power semiconductor.

\section{References}

Allard, B., Garrab, H. \& Morel, H. (2005). Electro-thermal simulation including a temperature distribution inside power semiconductor devices, International Journal of Electronics, vol.92, pp. 189-213, ISSN 0020-7217

Chester, J. \& Shammas, N. (1993). Thermal and electrical modelling of high power semiconductor devices, IEE Colloquium on Thermal Management in Power Electronics Systems, pp. 3/1 - 3/7, London, UK

Chung, Y. (1999). Transient thermal simulation of power devices with Cu layer, Proc. 11th International Symposium on Power Semiconductor Devices and ICs. ISPSD'99, pp. 257260, ISBN 0-7803-5290-4

Deskur, J. \& Pilacinski, J. (2005). Modelling of the power electronic converters using functional models of power semiconductor devices in Pspice, European Conference on Power Electronics and Applications, ISBN 90-75815-09-3

Gatard, E., Sommet, R. \& Quere, R. (2006). Nonlinear thermal reduced model for power semiconductor devices, Proc. 10th Intersociety Conference on Thermal and Thermomechanical Phenomena in Electronics Systems, ISBN 0-7803-9524-7

Kraus, R. \& Mattausch, H. (1998). Status and trends of power semiconductor device models for circuit simulation. IEEE Transactions on Power Electronics, vol.13, pp. 452 - 465, ISSN 0885-8993

Kuzmin, V., Mnatsakanov, T., Rostovtsev, I. \& Yurkov, S. (1993). Problems related to power semiconductor device modelling, Fifth European Conference on Power Electronics and Applications, pp. 113 - 117, ISBN 0-8529-6587-7

Maxim, A., Andreu, D., \& Boucher, J. (2000). A unified high accuracy SPICE library for the power semiconductor devices built with the analog behavioral macromodeling technique, Proc. 12th Int. Symp. on Power Semiconductor Devices and Ics, pp. 189 - 192, ISBN 0-7803-6269-1

Nelson, J., Venkataramanan, G. \& El-Refaie, A. (2006). Fast thermal profiling of power semiconductor devices using Fourier techniques, IEEE Transactions on Industrial Electronics, vol.53, pp. 521 - 529, ISSN 0278-0046

Pandya, K. \& McDaniel, W. (2002). A simplified method of generating thermal models for power MOSFETs, Proc. Eighteenth Annual IEEE Semiconductor Thermal Measurement and Management Symposium, ISBN 0-7803-7327-8

Schlogl, A., Mnatsakanov, T. \& Schroder, D. (1998). Temperature dependent behaviour of silicon power semiconductors-a new physical model validated by device-internal probing between $400 \mathrm{~K}$ and $100 \mathrm{~K}$, Proc. of the 10th Int. Symp. on Power Semiconductor Devices and ICs ISPSD, pp. 383 - 386, ISBN 0-7803-5100-2

Shammas, N., Rodriguez, M. \& Masana, F. (2002). A simple evaluation method of the transient thermal response of semiconductor packages, Microelectronics Reliability, vol.42, pp. 109-117, ISSN 0026-2714

Sunde, V., Jakopovic, Z. \& Cobanov, N. (2006). Simple Hybrid Electrothermal Simulation Procedure, 12th International Power Electronics and Motion Control Conference, pp. 617 - 620, ISBN 1-4244-0121-6

Wenthen, F. (1970). Computer-aided thermal analysis of power semiconductor devices. IEEE Transactions on Electron Devices, vol.17, pp. 765 - 770, ISSN 0018-9383 


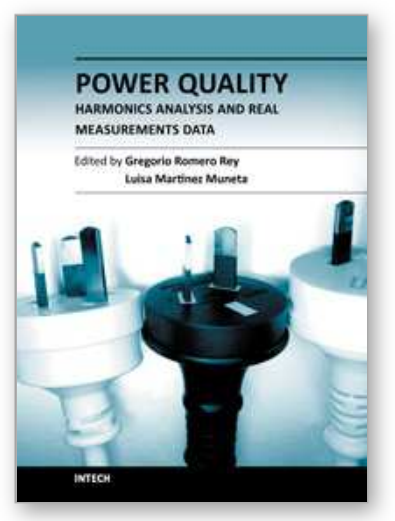

\author{
Power Quality Harmonics Analysis and Real Measurements Data \\ Edited by Prof. Gregorio Romero
}

ISBN 978-953-307-335-4

Hard cover, 278 pages

Publisher InTech

Published online 23, November, 2011

Published in print edition November, 2011

Nowadays, the increasing use of power electronics equipment origins important distortions. The perfect AC power systems are a pure sinusoidal wave, both voltage and current, but the ever-increasing existence of nonlinear loads modify the characteristics of voltage and current from the ideal sinusoidal wave. This deviation from the ideal wave is reflected by the harmonics and, although its effects vary depending on the type of load, it affects the efficiency of an electrical system and can cause considerable damage to the systems and infrastructures. Ensuring optimal power quality after a good design and devices means productivity, efficiency, competitiveness and profitability. Nevertheless, nobody can assure the optimal power quality when there is a good design if the correct testing and working process from the obtained data is not properly assured at every instant; this entails processing the real data correctly. In this book the reader will be introduced to the harmonics analysis from the real measurement data and to the study of different industrial environments and electronic devices.

\title{
How to reference
}

In order to correctly reference this scholarly work, feel free to copy and paste the following:

Adrian Plesca (2011). Thermal Analysis of Power Semiconductor Converters, Power Quality Harmonics Analysis and Real Measurements Data, Prof. Gregorio Romero (Ed.), ISBN: 978-953-307-335-4, InTech, Available from: http://www.intechopen.com/books/power-quality-harmonics-analysis-and-real-measurementsdata/thermal-analysis-of-power-semiconductor-converters

\section{INTECH}

open science | open minds

\section{InTech Europe}

University Campus STeP Ri

Slavka Krautzeka 83/A

51000 Rijeka, Croatia

Phone: +385 (51) 770447

Fax: +385 (51) 686166

www.intechopen.com

\section{InTech China}

Unit 405, Office Block, Hotel Equatorial Shanghai

No.65, Yan An Road (West), Shanghai, 200040, China

中国上海市延安西路65号上海国际贵都大饭店办公楼405单元

Phone: +86-21-62489820

Fax: $+86-21-62489821$ 
(C) 2011 The Author(s). Licensee IntechOpen. This is an open access article distributed under the terms of the Creative Commons Attribution 3.0 License, which permits unrestricted use, distribution, and reproduction in any medium, provided the original work is properly cited. 